\title{
Experimental Study on Pore Structure and Gas Desorption Characteristics of a Low Rank Coal: Impact of Moisture
}

\section{Ming-yi Chen ( $\nabla$ chenmingyi@stdu.edu.cn )}

Shijiazhuang Tiedao University

\section{Ya-pu Yang}

Shijiazhuang Tiedao University

\section{Xiao-yun Chen}

Shijiazhuang Tiedao University

\section{Fu-chao Tian}

China Coal Technology and Engineering Group Corp Shenyang Coal Research Institute

\section{Wei-li Sun}

China Coal Technology and Engineering Group Corp Shenyang Coal Research Institute

\section{Yu-meng Yang}

Shijiazhuang Tiedao University

\section{Tong-hao Zhang}

Shijiazhuang Tiedao University

\section{Research}

Keywords: Water adsorption, Pore structure, Fractal dimension, Methane desorption, Coal and gas outburst

Posted Date: December 8th, 2021

DOI: https://doi.org/10.21203/rs.3.rs-1110358/v1

License: (c) (1) This work is licensed under a Creative Commons Attribution 4.0 International License. Read Full License 


\section{Experimental study on pore structure and gas desorption characteristics of a \\ Low rank coal: Impact of moisture}

Chen Ming-yi ${ }^{\mathrm{ab}, \mathrm{c}} \mathrm{c}_{*}$, Yang Ya-pu ${ }^{\mathrm{a}, \mathrm{c}}$, Chen Xiao-yun ${ }^{\mathrm{a}}$, Tian Fu-chao ${ }^{\mathrm{d}}$, Sun Wei-lid, Yang Yu-menga, ${ }^{\mathrm{a}, \mathrm{b}}$, Zhang Tong-hao ${ }^{\mathrm{a}}$

a School of safety engineering and emergency management, Shijiazhuang Tiedao University,

Shijiazhuang 050043, China

b Hebei province technical innovation center of safe and effective mining of metal mines,

Shijiazhuang Tiedao University, Shijiazhuang 050043, China

c Key Laboratory of Roads and Railway Engineering Safety Control (Shijiazhuang Tiedao

University), Ministry of Education, shijiazhuang 050043, China

d State Key Laboratory of Coal Mine Safety Technology, China Coal Technology \&Engineering

Group Shenyang Research Institute, Shenfu Demonstration Zone 113122, China

*Corresponding author: Chen Ming-yi

Address: School of safety engineering and emergency management, Shijiazhuang Tiedao University,

Shijiazhuang 050043, China Tel.: +8631187936452 Fax: +8631187936452

E-mail address:

Chen Ming-yi chenmingyi@stdu.edu.cn

Yang Ya-pu_ yangyapu97@163.com

Chen Xiao-yun chenxiaoyun18@126.com

Tian Fu-chao tianfuchao@cumt.edu.cn

Sun Wei-li $\quad$ vealy_sun1989@163.com

Yang Yu-meng aqyangyumeng@stdu.edu.cn

Zhang Tong-hao th15732169205@163.com 
1 Abstracts: Coal and gas outburst is one of the most serious disasters for underground coal mining. The

2 water adsorbed on coal can leads to that the pore structure of moist coal is different from that of dry

3 coal, thereby affecting methane desorption characteristics of coal for the outburst risk prediction. In this

4 paper, the impact of moisture on pore structure and methane desorption performance were investigated.

5 The analysis on low-temperature nitrogen gas adsorption tests show that the micropores (pore diameter

$6<10 \mathrm{~nm})$ are most affected by the adsorbed water. In particular, for water-equilibrated coal sample at

$7 \quad 98 \%$ relatively humidity, the micropores less than $4 \mathrm{~nm}$ analyzed by DFT pore size distributions almost

8 disappear probably due to the blocking effect of the formed water clusters and capillary water. In this

case, the micropores can still contributes most sites for gas adsorption. Furthermore, the fractal dimension at relative pressure of $0-0.5\left(D_{1}\right)$ and $0.5-1\left(D_{2}\right)$ calculated by the Frenkel-Halsey-Hill model indicates that, when moisture content is less than $4.74 \%, D_{1}$ decreases rapidly while $D_{2}$ shows a slight change; whereas, further increases in moisture content results in that $D_{2}$ decreases significantly and $D_{1}$ remains at about 2.32. Further investigation shows that, below the equilibrium moisture content, the ultimate desorption volume $(A)$ and initial desorption rate $\left(V_{0}\right)$ are closely related to $D_{1}$, while the desorption constant $\left(K_{\mathrm{t}}\right)$ mainly depends on $D_{2}$. Therefore, the adsorbed moisture has significant negative impact on methane desorption performances by affecting characteristics of coal's pores.

Keywords: Water adsorption; Pore structure; Fractal dimension; Methane desorption; Coal and gas outburst

\section{Introduction}

Currently, although the casualties caused by coal mine disasters have been effectively controlled, coal and gas outburst is still one of the most serious disasters associated with coal mine (Fu et al. 2020; Wang et al. 2014b; Zhai et al. 2016). A coal and gas outburst is closely related to the methane 
desorption capacity of coal, and many methane desorption indices are used to predict the outburst risk (Wang et al. 2020b; Xue et al. 2020). Therefore, understanding the methane desorption characteristics of coal is critical for the prediction of coal and gas outburst. Coal is a porous medium with a highly developed pore system (Cheng and Pan 2020; Lu et al. 2021). Water in coal can be divided into two types: inherent moisture in coal matrix and free water in cleat system (Pan et al. 2010). The inherent moisture mainly exists in the absorbed state, which can occupy the surface sites of coal pores due to the physical adsorption and oxygen-containing functional group effects (Wang et al. 2021). Moreover, the existing of oxygen-containing functional groups (e.g. carboxylic and hydroxyl groups) adsorption sites are preferably occupied by water molecules ( $\mathrm{Li}$ et al. 2019). Therefore, the adsorption advantage of water molecules will weaken the capacity of coal adsorbing gas, thereby affecting desorption and migration of methane gas in coal body.

Many scholars have long been concerned about moisture influences on gas adsorption and desorption of coal through experimental, numerical simulation and mathematical theory methods. The existence of water can significantly reduce the methane adsorption capacity of coal (Busch and Gensterblum 2011; Nie et al. 2016), which is mainly due to the competitive adsorption of water and methane and the advantage of coal adsorbing water molecules (Gensterblum et al. 2014; Xiang et al. 2014). It has been reported that $2 \%$ moisture content can result in an approximately $20 \%$ reduction in both $\mathrm{CH}_{4}$ and $\mathrm{CO}_{2}$ adsorption capacity of moist coal (Clarkson and Bustin 2000). The impact of water on methane adsorption capacity is also related to the metamorphic degree of coal. Dry coal shows a trend of first falling and then rising with increasing coal rank, whereas the methane adsorption capacity of the water-equilibrated coal increases slightly with coal rank (Laxminarayana and Crosdale 2002). It is further found that the adsorbed water can induces the reduction in methane adsorption capacity of a 
bituminous coal and the non-adsorbed water has no effect; in contrast, for anthracite coal, both the two form of water have remarkably weaken on methane adsorption, which is considered to be related to the difference in pore structure between the two coal samples (Wang et al. 2020a). Besides, water also has great weakening impact on methane desorption and diffusion capacities of coal (Liu et al. 2019; Pan et al. 2010). Combined with unipore, bidisperse and other diffusion models, it is observed that increasing moisture content causes both micropores and macropores diffusion coefficients to decrease for different rank coals (Guo et al. 2018; Wang et al. 2017). Other studies further show that increasing equilibrium moisture content can induces the continual decreases in diffusivity for anthracite coal and the U-shaped change in diffusivity for bituminous coal. This may be caused by the different moisture effects between the reduction in adsorbed gas volume and the decrease of pore space for various rank coals (Wang et al. 2014a). Furthermore, increasing moisture content can also decreases the methane desorption volume and velocity of coal, which has been widely accepted by scholars (Chen and Cheng 2015; Meng et al. 2020; Zhang et al. 2018).

Generally, coal with $R_{0, \max }$ less than $0.65 \%$ is classified as low-rank coal in China (Wang et al. 2017), which includes lignite and some long-flame coal. Low-rank coal generally features a higher adsorbed water content than middle-high rank coals, because low-rank coal has a larger porosity, specific surface area (SSA) and more oxygen-containing functional groups (Chen et al. 2018; Yu et al. 2013). Statistics show that in China, the moisture content of lignite is $10-28 \%$ and that of long-flame coal mostly is $3-12 \%$ (Guo et al. 2015). Hence, more studies on the influence of adsorbed water on the methane desorption characteristics of low-rank coal are needed.

In this paper, a typical long-flame coal was used to perform the following studies: (1) water adsorption characteristics of coal and pore structure of water-equilibrated coal at different relatively 
humidity, (2) the relationships between adsorbed moisture content and fractal dimension of coal pores, (3) the impact of adsorbed moisture on methane desorption performances and its relations with fractal dimension.

\section{Experiment and method}

\subsection{Coal preparation and Basic parameters}

\subsubsection{Basic parameters}

The low rank coal sample was selected from the No. 2 coal seam in the Yuanzigou coal mine, Baoji city, Shaanxi Province. The geological survey data show that the moisture content of the No. 2 coal seam on air dry basis is $3.60-11.28 \%$. Several kilograms of fresh lump coal were collected from the working face, and various sizes of coal particles were prepared by crushing and screening. Following the ISO 17246:2010 standard, the coal sample with sizes of $0.074-0.20 \mathrm{~mm}$ was selected to perform the proximate analysis by an automatic proximate analyzer. The vitrinite reflectance of coal reflects the coalification degree, which was determined by following the ISO 7404-5:2009 standard. The ash content on air dry basis $\left(A_{\text {ad }}\right)$, volatile matter on dry ash free basis $\left(V_{\text {daf }}\right)$, fixed carbon on air dry basis $\left(F C_{\mathrm{ad}}\right)$, maximum vitrinite reflectance $\left(R_{\mathrm{o}, \max }\right)$ are shown in Table 1.

Table 1 Basic parameters of coal sample.

\begin{tabular}{cccccc}
\hline Sample & $R_{\mathrm{o}, \max } / \%$ & $M_{\mathrm{ad}} / \%$ & $A_{\mathrm{ad}} / \%$ & $V_{\mathrm{daf}} / \%$ & $F C_{\mathrm{ad}} / \%$ \\
\hline Long-flame coal & 0.65 & 6.33 & 26.59 & 40.53 & 39.90 \\
\hline
\end{tabular}

\subsubsection{Preparation of moist coal samples}

First, the coal samples with particle sizes of $0.2-0.25 \mathrm{~mm}$ were placed in a vacuum drying oven at $378 \mathrm{~K}$ for at least $8 \mathrm{~h}$ to remove the original moisture. Eight saturated salt solutions were selected to prepare the water-equilibrated coal sample under a constant relatively humidity $(R H)$ condition. The $R H$ was $11 \%$ for $\mathrm{LiCl}, 23 \%$ for $\mathrm{CH}_{3} \mathrm{COOK}, 33 \%$ for $\mathrm{MgCl}_{2}, 43 \%$ for $\mathrm{K}_{2} \mathrm{CO}_{3}, 57 \%$ for $\mathrm{NaBr}, 75 \%$ for $\mathrm{NaCl}, 85 \%$ for $\mathrm{KCl}$, and $98 \%$ for $\mathrm{K}_{2} \mathrm{SO}_{4}$ at a room temperature of $293 \mathrm{~K}$. Approximately $5 \mathrm{~g}$ of coal 
sample was placed into glassware containing saturated salt solution, and the glassware was sealed with vacuum silica gel. A high-precision electronic balance (FA2204) was used to weigh the coal samples at $8 \mathrm{~h}$ intervals. When the quality of the sample remains steady, it was considered that the water adsorption equilibrium was achieved under the corresponding relative humidity $(R H)$ conditions. Subsequently, the moisture content of the coal sample under different $R H$ conditions was calculated by the following equation:

$$
M=\frac{\left(m_{\text {moist }}-m_{d r y}\right)}{m_{d r y}}
$$

Where $M$ is the moisture content, \%; $m_{\text {moist }}$ is the weight of moist sample at a certain $R H$, g; and $m_{\text {dry }}$ is the weight of dry sample, $\mathrm{g}$. The water adsorption test was repeated twice and the mean values of moisture content at different relative humidity were determined for further study.

Furthermore, the water adsorption characteristic of the studied coal was analyzed by a modified Guggenheim-Anderson-de Boer (M-GAB) model. The M-GAB model is based on the BET and GAB model, which has been proved to be a good characterization of water vapor adsorption on porous materials (Zou et al. 2016). The M-GAB model, like GAB and M-Dent model (Duan and Li 2018), assumes water molecules adsorb on two sites: primary adsorption sites and secondary adsorption sites and one molecule occupies $\alpha$ sites when being adsorbed. The M-GAB model can be described by the following equation:

$$
M=\frac{M_{0} * C * K * x^{\alpha}}{\left(1-K * x^{\alpha}\right)\left(1-K * \chi^{\alpha}+C * K * x^{\alpha}\right)}
$$

Where $M_{0}$ is the monolayer adsorption capacity, $x$ is relative humidity, $C$ and $K$ are the adsorption constants related to primary sites and secondary sites, respectively, and $\alpha$ represents the heterogeneity of the adsorption system. The water adsorption amounts of primary and secondary sites have the following relationships (Andrade et al., 2011): 
113

\subsection{Low-temperature nitrogen gas adsorption test}

Low-temperature nitrogen gas adsorption $\left(\mathrm{LN}_{2} \mathrm{GA}\right)$ was an important physical method to characterize the nanopores of porous media. In this study, the test instrument was an Autosorb-iQ2 analyzer (Quantachrome Ins, USA). The $\mathrm{N}_{2}$ ad/desorption isotherms at a $P / P_{0}$ of $0.001-0.995$ of coal samples were measured. Before the $\mathrm{LN}_{2} \mathrm{GA}$ tests, according to the moist coal sample preparation processes in Section 2.1.2, the coal samples with different water content were prepared. Then, the moist coal samples were placed in liquid $\mathrm{N}_{2}$ environments at a temperature of $\sim 77 \mathrm{~K}$ for several minutes. Under these conditions, the moist samples were frozen so that the loss of pre-adsorbed water could be ignored. At the same time, the vacuum pumping step was omitted to avoid the loss of water in the tested samples.

\subsection{Tests and Analytical methods for methane desorption in coal}

\subsubsection{Methane desorption tests}

The bulk desorption method (Zhang 2008) was applied to perform the methane desorption test of coal samples with particle sizes of $0.2-0.25 \mathrm{~mm}$. First, approximately $50 \mathrm{~g}$ of coal sample was put into a coal sample tank. To reduce the loss of water from the coal sample as much as possible, the vacuum pumping time was operated for no longer than $30 \mathrm{~min}$. Then, the methane gas with a purity of $99.99 \%$ was pumped into the coal sample tank to a gas pressure, and the coal sample tank was put into a stable temperature water bath at $303.15 \mathrm{~K}$. Subsequently, the gas pressure of the coal sample tank was adjusted to a predetermined pressure $(1 \mathrm{MPa})$. When the pressure gauge remained constant for $8 \mathrm{~h}$, it is deemed that the gas-containing coal sample has achieved the adsorption equilibrium state. Finally, the 
133

free gas of the coal sample tank was removed, and then a methane desorption test of coal sample can be performed. The test time was conducted for $120 \mathrm{~min}$, and the methane desorption volume of coal at regular intervals and the ultimate desorption volume $\left(Q_{\infty}\right)$ were recorded. The moisture content of the test sample was measured by the weighing method after the methane desorption test.

\subsubsection{Analytical methods of desorption data}

Currently, numerous of mathematical equations have been proposed to describe the gas desorption law of coal particles (Cheng et al. 2010). Among them, the Airey-type and Winter-type equations are often used to analyze the law of underground coal seam gas desorption and emission.

Airey believed that the coal body could be regarded as a material composed of separated blocks containing fractures and proposing the following formula (Airey 1968):

$$
Q_{t}=A\left[1-\exp \left\{-\left(\frac{t}{t_{0}}\right)^{n}\right\}\right]
$$

where $Q_{\mathrm{t}}$ is the gas desorption volume at time $t, \mathrm{~cm}^{3} / \mathrm{g} ; A$ is the ultimate desorption volume, $\mathrm{cm}^{3} / \mathrm{g} ; t_{0}$ is the desorption time constant; and $n$ is a coefficient.

In Winter's theory, when the gas pressure was removed, the change in the gas desorption rate with time can be described by the following power function (Winter and Janas 1975):

$$
V_{t}=V_{a}\left(\frac{t}{t_{a}}\right)^{-K_{t}}
$$

After mathematical integration, the relationship between methane desorption volume and time can be obtained, as shown in the following equation:

$$
Q_{t}=\frac{V_{1}}{1-K_{t}} t^{1-K_{t}}
$$

where $Q_{\mathrm{t}}$ is the cumulative desorption volume at time $t, \mathrm{~cm}^{3} / \mathrm{g} ; V_{1}$ and $V_{\mathrm{a}}$ are the methane desorption rates at times $t_{1}$ and $t_{\mathrm{a}}$, respectively, $\mathrm{cm}^{3} /(\mathrm{g} \cdot \mathrm{min})$; and $k_{\mathrm{t}}$ is a constant that reflects the degree of attenuation of the desorption rate (Banerjee 1988). 


\section{Experimental results}

\subsection{Water adsorption isotherms}

The M-GAB model fitting for water adsorption data of the studied coal sample is shown in Figure

1. According to the International Union of Pure and Applied Chemistry (IUPAC) classification (Lowell et al. 2004), the adsorption curve belongs to type II isotherms. The M-GAB model has excellent fitting effect with a $R^{2}$ value of 0.9975 . The water adsorption amount shows stage characteristics. Under the conditions of $R H<0.2$ and $R H>0.8$, the water adsorption amount increases rapidly. When $R H$ ranges from 0.2 to 0.8 , the growth of water adsorption capacity is relatively gentle.

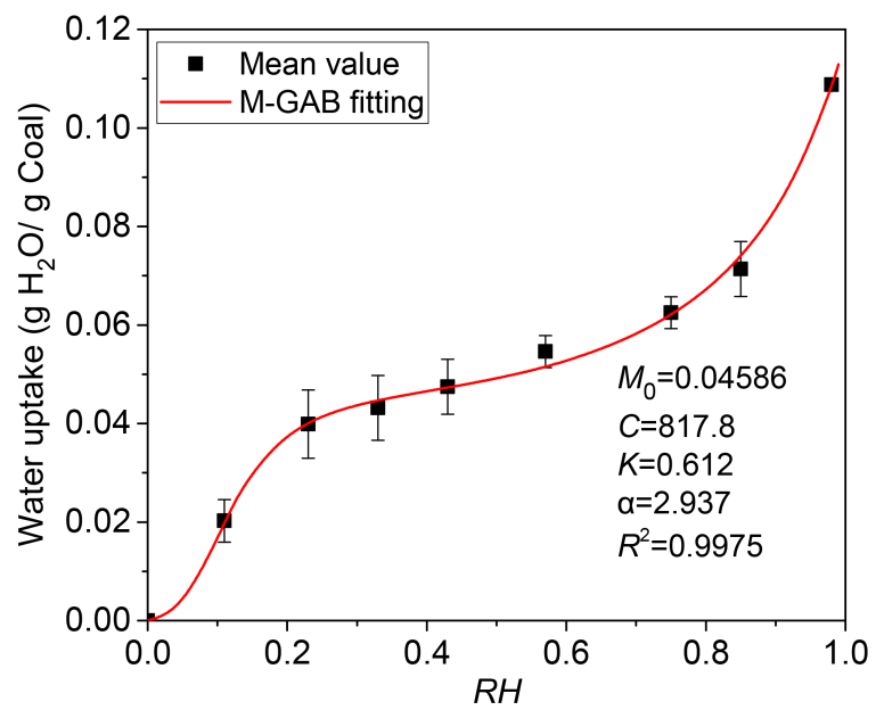

Figure 1 The M-GAB model fitting for water adsorption of the studied sample.

\section{2 $\mathrm{LN}_{2} \mathrm{GA}$ isotherms}

The $\mathrm{LN}_{2} \mathrm{GA}$ adsorption and desorption isotherms of coal samples are illustrated in Figure 2. The adsorption isotherms of dry and moist samples belong to type II of the IUPAC classification. With the moisture content increases, the slope of nitrogen adsorption curve decreases at the pressure range of 0.1 to 0.9 . For the maximum nitrogen adsorption amount, the dry coal sample is $20.24 \mathrm{~cm}^{3} / \mathrm{g}$, whereas, that of water-equilibrated coal sample at $98 \% R H(M=10.88 \%)$ is reduced by nearly $50 \%$. In the low relative pressure range $\left(P / P_{0}<0.01\right)$, the nitrogen adsorption capacity of coal samples generally 
172

173

174

increases significantly, which is mainly related to the micropores filling effect caused by a large number of micropores in coal (Hong et al. 2019; Kondo et al. 2005). It can be observed that the nitrogen adsorption curves at $P / P_{0}<0.1$ become flatter with increasing moisture content, which reflects that the micropores filling effect is weakened for gas adsorption on moist coal samples. When the $P / P_{0}$ is close to 1.0, all adsorption curves increase sharply, which indicates that water has a weak impact on nitrogen gas adsorption in larger scale pores of coal.
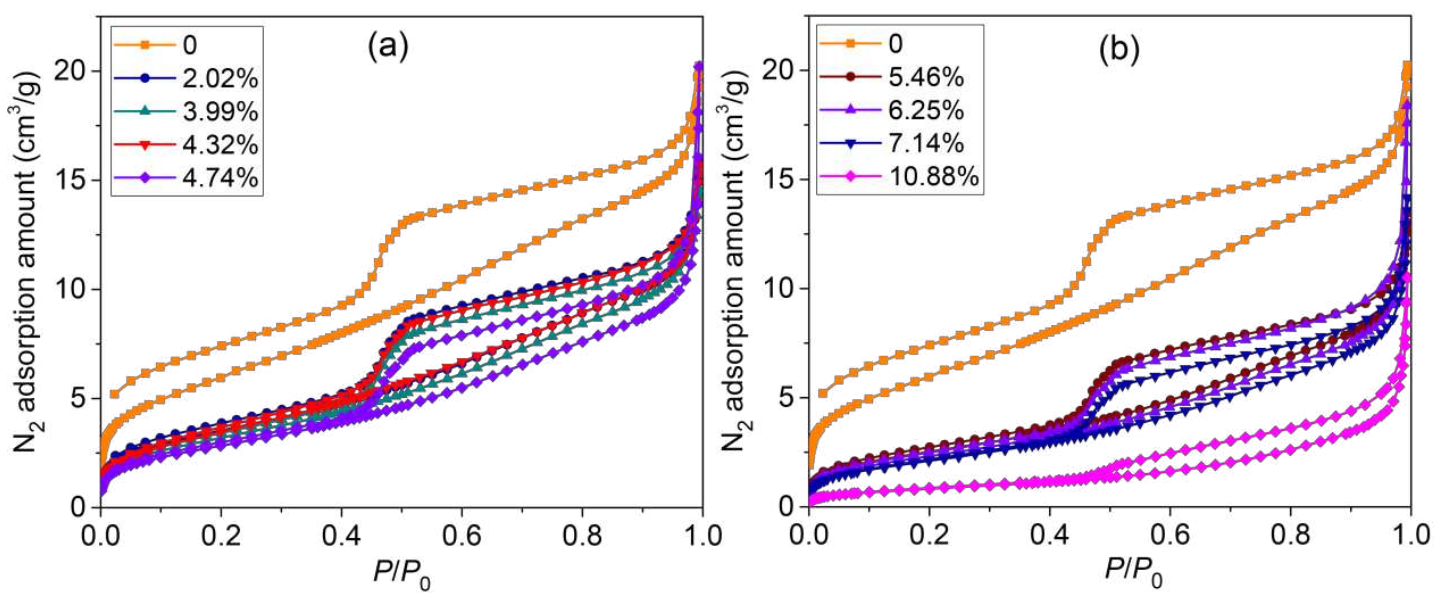

Figure 2 Low-temperature nitrogen ad/desorption isotherms of coal samples.

In addition, all coal samples show a prominent adsorption hysteresis characteristics, the features of the hysteresis loop correspond to types H3 and H4 in the IUPAC classification (Thommes et al. 2015), and its size tends to decrease with increasing moisture content. The coal samples with moisture content less than $7.14 \%$ (corresponding to $R H$ of $85 \%$ ) exhibit an inflection point of the desorption curve at the $P / P_{0}$ around 0.45 , which is considered to be related to the existence of ink-bottle pores (Liu et al. 2021; Qi et al. 2017). The desorption curve of coal sample around the inflection point gradually shrinks with moisture content increases. When the moisture content increases to the maximum equilibrium moisture content $(10.88 \%)$, the inflection point of desorption curve almost disappears.

\subsection{Methane desorption characteristics}

For the methane desorption isotherms at gas pressure of $1 \mathrm{MPa}$, the fit curves of the Winter-type 
and Airey-type equations are shown in Figure 3. The desorption process can be divided into rapid growth period (1)), stable growth period (2) and slow growth period (3)). It can be observed that the cumulative desorption amount shows a monotonous upward trend of the parabola with increasing desorption time. Besides, the cumulative desorption amount of coal samples decreases with the moisture content increases.
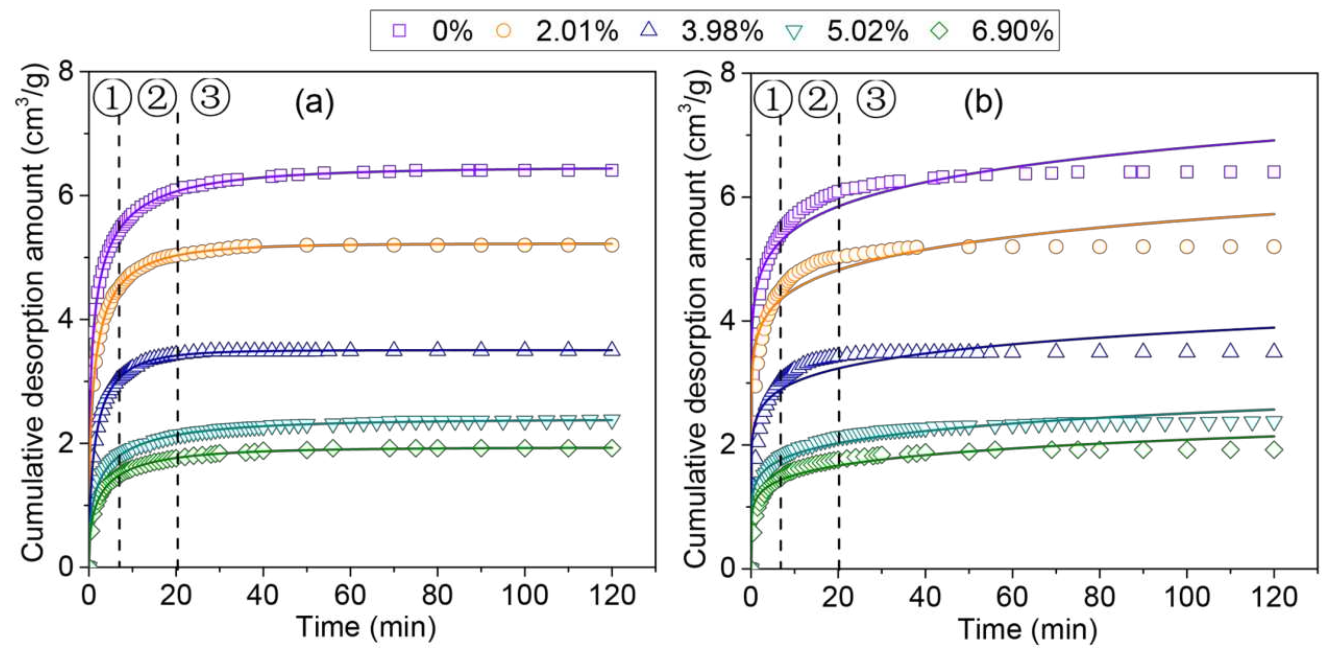

Figure 3 Methane desorption data and fit curves of coal samples at methane pressure of $1 \mathrm{MPa}$; (a) Airey-type fit; (b) Winter-type fit.

The fit results of the Airey-type and Winter-type equations are shown in Table 2. The correlation coefficient $R^{2}$ of the Airey-type equation is $0.9989-0.9998$; for the Winter-type equation, it is 0.8670 0.9373. The Airey-type equation exhibits a higher fit accuracy than the Winter-type equation. The parameters $A$ and $V_{1}$ represent the ultimate methane desorption capacity and the initial rate of methane desorption, respectively (Chen et al. 2017; Guo et al. 2018). Obviously, increasing the moisture content can causes a significant reduction in methane desorption capacity.

Table 2 Fitting results of the tested samples by Airey-type and Winter-type equations

\begin{tabular}{|c|c|c|c|c|c|c|c|}
\hline \multirow{2}{*}{$\begin{array}{c}\text { Moisture } \\
\text { content } \\
1 \% \\
\end{array}$} & \multicolumn{4}{|c|}{ Airey's equation } & \multicolumn{3}{|c|}{ Winter's equation } \\
\hline & $\begin{array}{c}A \\
/\left(\mathrm{cm}^{3} / \mathrm{g}\right) \\
\end{array}$ & $t_{0} / \mathrm{min}$ & $n$ & $R^{2}$ & $\begin{array}{l}V_{1} /\left(\mathrm{cm}^{3} /\right. \\
(\mathrm{g} \cdot \mathrm{min}))\end{array}$ & $k_{\mathrm{t}}$ & $R^{2}$ \\
\hline 0 & 6.460 & 1.406 & 0.387 & 0.9998 & 0.413 & 0.907 & 0.9373 \\
\hline 2.01 & 5.225 & 1.530 & 0.463 & 0.9997 & 0.347 & 0.904 & 0.9013 \\
\hline 3.98 & 3.504 & 1.901 & 0.554 & 0.9997 & 0.245 & 0.897 & 0.8670 \\
\hline 5.02 & 2.392 & 3.329 & 0.446 & 0.9989 & 0.180 & 0.868 & 0.9290 \\
\hline 6.90 & 1.934 & 3.175 & 0.484 & 0.9989 & 0.153 & 0.861 & 0.9139 \\
\hline
\end{tabular}


The errors of parameter $A$ are $0.22-0.85 \%$ for methane pressure of $1 \mathrm{MPa}$, so parameter $A$ is very close desorption behavior of coal.

Table 3 Results of methane desorption amounts in different desorption periods.

\begin{tabular}{cccc|c}
\hline Moisture content $/ \%$ & $Q_{1} /\left(\mathrm{cm}^{3} / \mathrm{g}\right)$ & $Q_{3 \sim 5} /\left(\mathrm{cm}^{3} / \mathrm{g}\right)$ & $Q_{\infty} /\left(\mathrm{cm}^{3} / \mathrm{g}\right)$ & $\left|\frac{A-Q_{\infty}}{Q_{\infty}}\right|$ \\
\hline 0 & 3.791 & 0.413 & 6.406 & 0.85 \\
2.01 & 2.950 & 0.405 & 5.199 & 0.50 \\
3.98 & 1.778 & 0.325 & 3.496 & 0.22 \\
5.02 & 1.018 & 0.177 & 2.380 & 0.54 \\
6.90 & 0.857 & 0.172 & 1.922 & 0.63 \\
\hline
\end{tabular}

\section{Analysis and Discussion}

\subsection{Water adsorption behavior of coal} adsorption. An inflection point around $R H$ of 0.2 can be observed in the M-GAB fitting curve, indicating the completion of monolayer coverage and the beginning of multilayer adsorption

222 (Thommes et al. 2015). When the $R H$ exceeds 0.5 , the primary adsorption approach the dotted line 
then the water clusters gradually form (Charrière and Behra 2010). As the $R H$ increases, the water uptake increases sharply at the region of $R H>0.8$, which is related to the capillary condenstation of water in pores.

Besides, in the M-GAB model, $C$ relates to adsorption energies of water molecules on primary sites, while $K$ associates with adsorption energies of the interaction between water molecules and adsorbed water molecules at secondary sites (Zou et al. 2016). For the studied coal sample, the value of $C$ is far larger than that of $K$, which is mainly due to that the weak interactions of coal-water molecules need more energy than the strong interactions of water-water molecules (Duan and Li 2018; Charrière and Behra 2010).

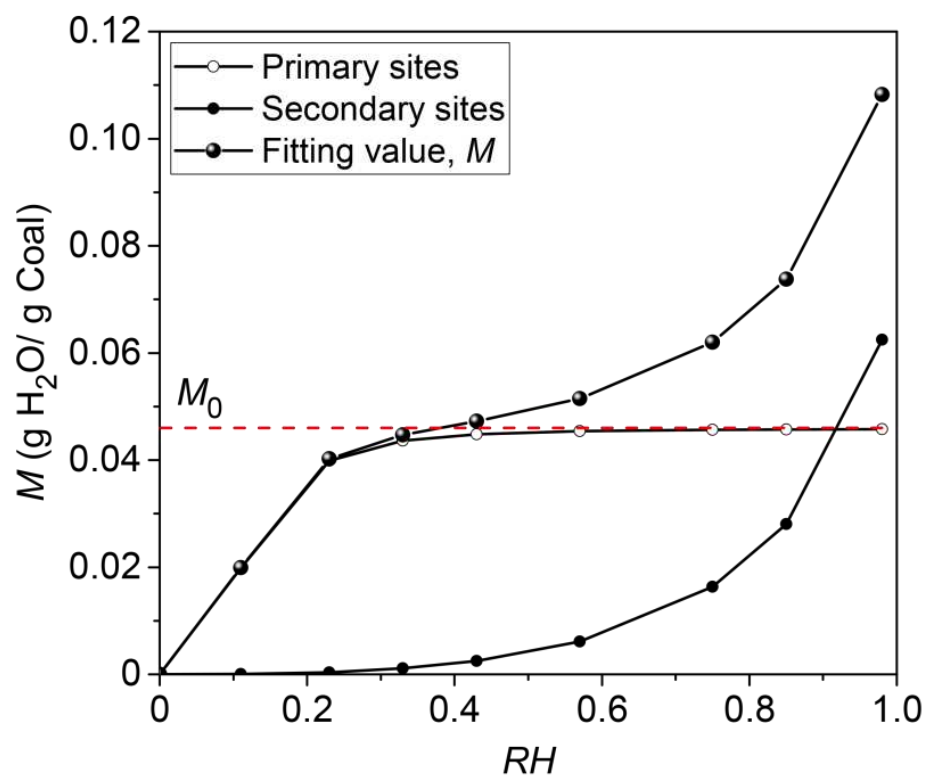

Figure 4. Amount of water adsorption on primary sites and secondary sites.

\subsection{Impact of water on pore structure of coal}

\subsection{1 $\mathrm{N}_{2}-\mathrm{SSA}$ and $\mathrm{N}_{2}-\mathrm{PV}$}

The pore size classification method proposed by В.В. ХОДОТ has widely used, and coal pores are divided into five categories (Chen et al. 2015; Jiang et al. 2016). Among them, micropores $(d<10 \mathrm{~nm})$ constitutes gas adsorption volume of coal, transition pores $(10<d<100 \mathrm{~nm})$ is the gas diffusion space, 
240 The pore diameter of $100 \mathrm{~nm}$ is always considered to be a cut point for gas diffusion and seepage

241 (Chen et al., 2017), and mesopores $(100<d<1000 \mathrm{~nm})$ forms a slow seepage space. In this paper, after

242 integrating the pore parameters from the QSDFT model $(1-10 \mathrm{~nm})$ and BJH model $(10-300 \mathrm{~nm})$, the

243 specific surface area (SSA), pore volume (PV) of different scales pores (micropores, transition pores,

244 mesopores) are calculated, as illustrated in Table 4. When the moisture content increases to the

245 equilibrium moisture content of $2.02 \%$ (corresponding to $R H$ of $11 \%$ ), the total SSA can be decreased

246 by about $39.3 \%$. With increasing moisture content, both the total SSA and total PV tend to decrease,

247 whereas the average pore diameter (PD) shows an increase tendency. For the water-equilibrated coal

248 sample at $98 \% R H(M=10.88 \%)$, the total SSA and total PV were reduced to $16.31 \%$ and $53.47 \%$,

249 respectively. That indicates that the adsorbed water can leads to a significant reduction in the SSA of

250 coal.

251

Table 5 Pore parameters of coal samples from $\mathrm{LN}_{2} \mathrm{GA}$ tests.

\begin{tabular}{|c|c|c|c|c|c|c|c|c|c|c|}
\hline \multirow{2}{*}{$\begin{array}{c}\text { Sample } \\
\text { no. }\end{array}$} & \multirow{2}{*}{$\begin{array}{c}\text { Mean } \\
\text { moisture } \\
\text { content }(\%)\end{array}$} & \multicolumn{4}{|c|}{$\mathrm{SSA}\left(\mathrm{m}^{2} / \mathrm{g}\right)$} & \multicolumn{4}{|c|}{$\mathrm{PV}\left(\times 10^{-3} \mathrm{~cm}^{3} / \mathrm{g}\right)$} & \multirow{2}{*}{$\begin{array}{l}\mathrm{PD} \\
(\mathrm{nm})\end{array}$} \\
\hline & & S1 & S2 & $\mathrm{S} 3$ & Total & V1 & V2 & V3 & Total & \\
\hline YZG1 & 0 & 16.44 & 1.12 & 0.096 & 17.66 & 18.79 & 7.20 & 4.83 & 30.82 & 5.66 \\
\hline YZG2 & 2.02 & 9.59 & 1.02 & 0.101 & 10.71 & 12.52 & 6.86 & 4.91 & 24.28 & 7.51 \\
\hline YZG3 & 3.99 & 8.72 & 1.03 & 0.096 & 9.85 & 11.75 & 6.98 & 5.09 & 23.82 & 7.97 \\
\hline YZG4 & 4.32 & 9.47 & 1.01 & 0.098 & 10.57 & 12.52 & 6.76 & 4.84 & 24.12 & 7.29 \\
\hline YZG5 & 4.74 & 7.68 & 1.01 & 0.24 & 8.93 & 10.53 & 7.26 & 13.50 & 31.29 & 11.63 \\
\hline YZG6 & 5.46 & 6.80 & 0.96 & 0.094 & 7.85 & 9.55 & 6.50 & 4.74 & 20.79 & 8.88 \\
\hline YZG7 & 6.25 & 6.23 & 0.99 & 0.21 & 7.43 & 8.91 & 7.33 & 10.98 & 27.23 & 12.38 \\
\hline YZG8 & 7.14 & 5.65 & 0.96 & 0.13 & 6.73 & 8.20 & 6.84 & 6.80 & 21.84 & 10.81 \\
\hline YZG9 & 10.88 & 1.95 & 0.79 & 0.14 & 2.87 & 3.35 & 5.94 & 7.19 & 16.48 & 20.50 \\
\hline
\end{tabular}

Note: $\mathrm{Si}(\mathrm{Vi})$ represents the SSA and PV of micropores, transition pores and mesopores, respectively, where $\mathrm{i}=1,2,3$. 

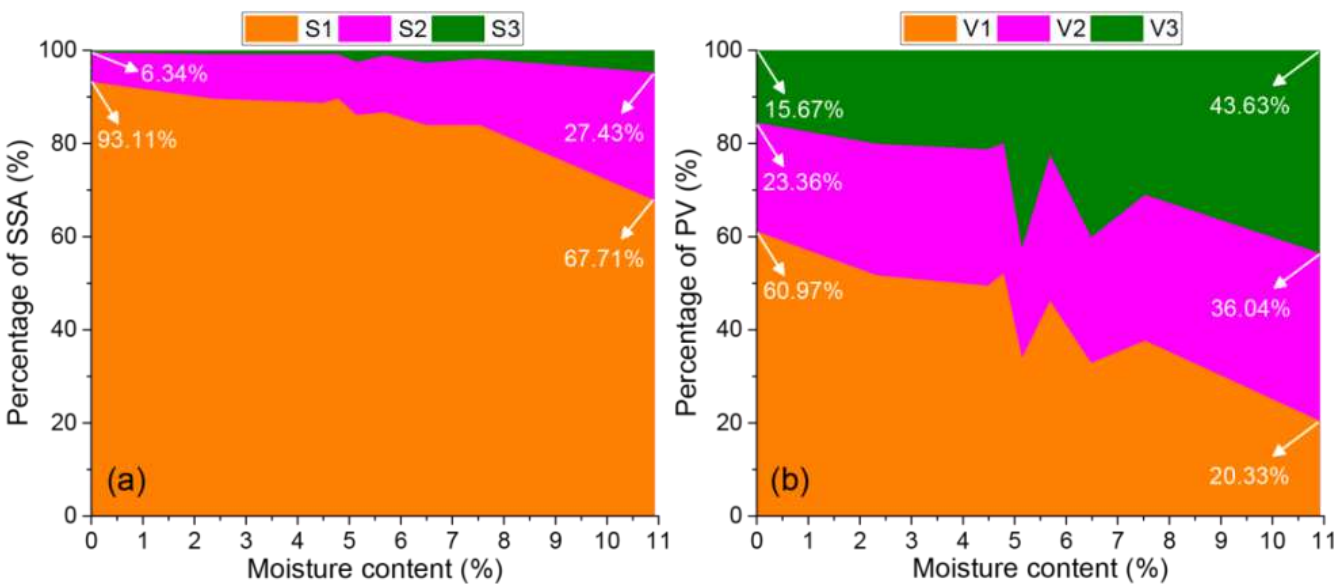

Figure 5. Change in percentage of SSA and PV of different scale pores with moisture content.

The percentages of SSA and PV of different scale pores (micropores, transition pores, mesopores) are shown in Figure 5. The micropores SSA of sample YZG1 accounts for 93.11\%, which indicates that the micropores plays a key role in gas adsorption at dry condition. The percentage of micropores SSA shows a decreasing trend with increasing moisture content, and that of sample YZG9 decreased to the lowest value $(67.71 \%)$. This means that the micropores can still contribute most sites for nitrogen adsorption on water-equilibrated coal samples. For pore volume, with increasing moisture content, the percentage of micropores volume also shows a decreasing trend, and $60.97 \%$ is for sample YZG1 at dry condition and only $20.33 \%$ is for sample YZG9 that is attained at water-equilibrated condition of $98 \% R H$. In contrast, the percentage of SSA and PV of both transition pores and mesopores show an increasing trend. Therefore, water can significantly reduce the SSA and PV of coal pores. In particular, the micropores $(d<10 \mathrm{~nm})$ are most significantly weakened owing to the existence of water.

\subsubsection{Pore size distribution}

Thommes et al. (2015) indicated that the BJH method is more suitable for pore size analysis of mesopores and larger pores $(>10 \mathrm{~nm})$, and the DFT method can provides a reasonably reliable assessment of the nanopore size distributions. In this paper, both DFT and BJH models are employed to investigate the PSDs (pore size distributions) of pores with the size of 1-300 nm. The BJH-PSDs 
curves of the coal samples are illustrated in Figure 6. All samples show multi-peak distribution characteristics, and there are a large number of nanopores in the size range of 3-300 nm. With increasing moisture content, the $\mathrm{dV}(\mathrm{d})$ value of coal samples gradually approach the $\mathrm{X}$-axis, especially for micropores $(d<10 \mathrm{~nm})$. The DFT-PSDs curves of coal samples are shown in Figure 7. The DFT $\mathrm{dV}(\mathrm{d})$ plots of coal samples with moisture content less than $7.14 \%$ mainly exhibit bi-peak values at $\sim 1.1 \mathrm{~nm}$ and $\sim 5.0 \mathrm{~nm}$, whereas, that of sample YZG9 $(M=10.88 \%)$ shows an uni-peak at $\sim 5.6 \mathrm{~nm}$. The DFT $d V(d)$ value tends to decrease with increasing moisture content, and when the moisture content reaches $10.88 \%$, the peak value of $\mathrm{dV}(\mathrm{d})$ approaches 0 at $\sim 1.1 \mathrm{~nm}$, thereby indicating that pores less than $4 \mathrm{~nm}$ almost disappear for water-equilibrated coal sample YZG9. For both DFT-PSDs and BJH-PSDs curves, there is no significant difference in the PSDs of pores greater than $10 \mathrm{~nm}$ for coal samples with different moisture content. Therefore, water mainly has a significant impact on micropores $(\mathrm{d}<10 \mathrm{~nm})$ of coal, which can be attributed to the adsorption of water on coal surface. Under the condition of low moisture content, the effective sites for $\mathrm{CH}_{4}$ or $\mathrm{N}_{2}$ molecules are decreased by the preferential adsorption of water molecules (Gensterblum et al. 2014; Gensterblum et al. 2013). With a further increase in moisture content, the multilayer adsorption will occurs and the thickness of water molecule layers becomes significant. The process can results in the formation of water clusters (Do and Do, 2009; Charrière and Behra, 2010). And further the growth of water clusters and the capillary condensation will fill up some small pores. With a further increase in $R H$, the adsorbed moisture content of coal is enhanced (Figure 1). Especially for the water-equilibrated coal sample YZG9 at $98 \% R H$, some pore throats can be blocked by the adsorbed water, thereby hindering the intrusion of gas molecules into the micropores. Thus the available nanopores for methane molecules adsorption on the water-equilibrated coal at $98 \% R H$ are mainly larger-scale pores (pore diameter $>4$ 
$\mathrm{nm})$.
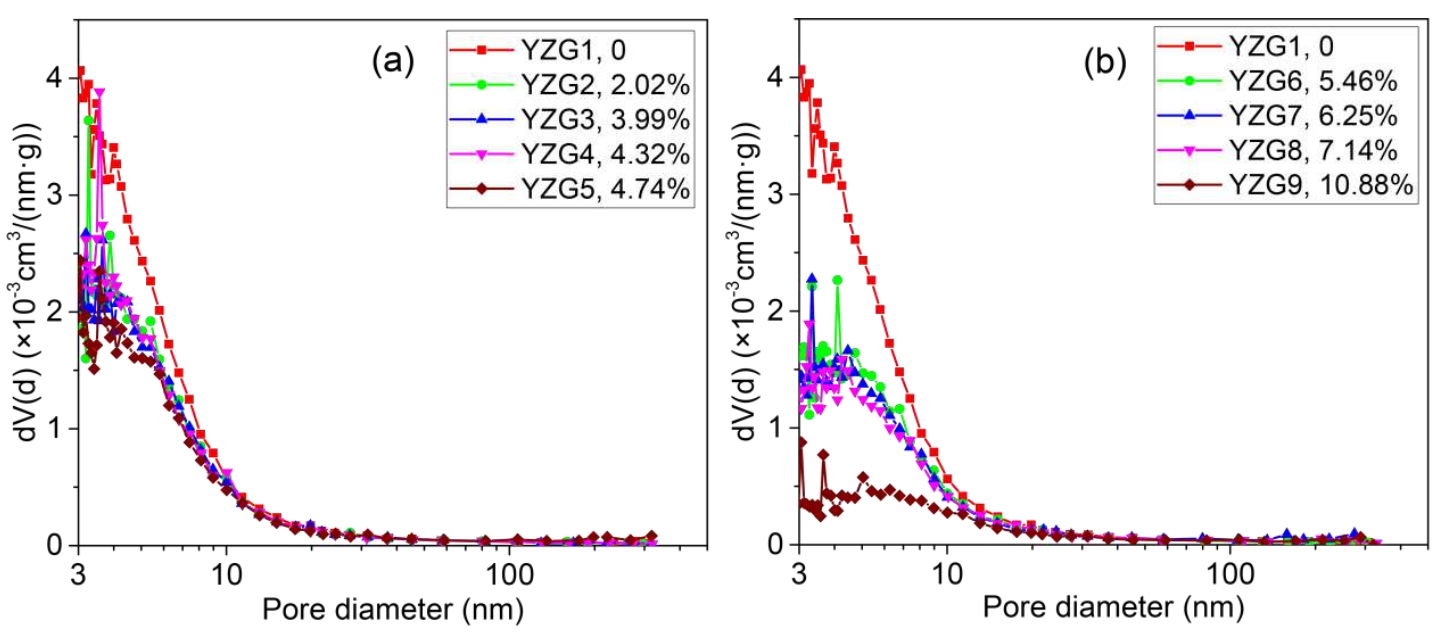

Figure 6 BJH-PSDs curves of coal samples.
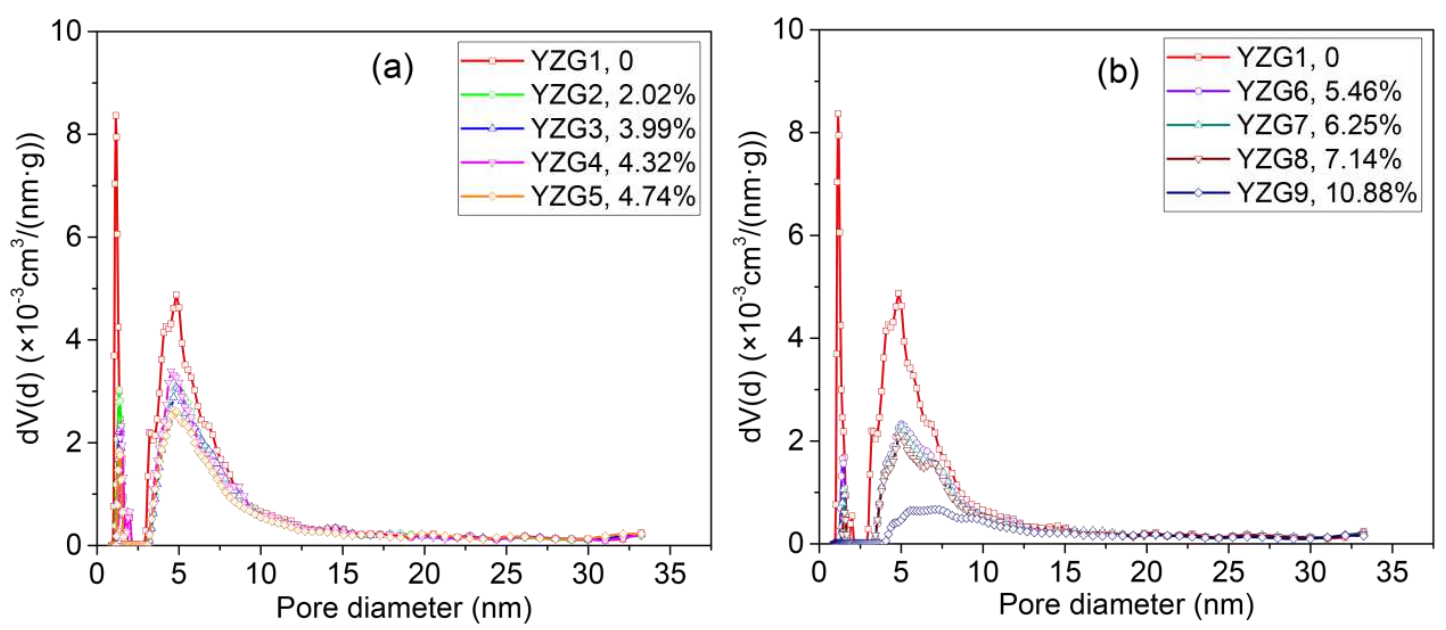

Figure 7 DFT-PSDs curves of coal samples.

\section{8}

299

\subsection{Fractal characteristics of coal pores under moist condition}

Based on the $\mathrm{LN}_{2} \mathrm{GA}$ data, the fractal dimension can be determined by the fractal Frenkel-Halsey-Hill (FHH) equation (Ni et al. 2020; Si et al. 2021; Liu and Nie 2016). It can be described by the following expression:

$$
\ln V=A\left[\ln \ln \left(\frac{P_{0}}{P}\right)\right]+B
$$

Where $V$ is the gas adsorption amount at adsorption equilibrium pressure $P ; P_{0}$ is the saturated gas pressure; $A$ is the slope of the fitting line, which is linear with the fractal dimension $D$, and there are two mathematical expressions for $A$ and $D$, namely, $A=D-3$ and $A=(D-3) / 3$; and $B$ is a constant. The 
306

307

fractal dimension, $D$ ranges from 2 to 3 , which can reflects the irregularity of coal pores. The closer $D$ is to 2 , the smoother the pore surface is; and the closer $D$ is to 3 , the more complex the pore surface is. Low-temperature nitrogen desorption isotherms is generally used to calculate the fractal dimension, because the corresponding adsorption state is more stable ( $\mathrm{Li}$ et al. 2015). In the region of $P / P_{0}<0.5$, the adsorption and desorption curves essentially parallel and even coincide, while in the region of $P / P_{0}>0.5$, there is significant adsorption hysteresis. This phenomenon suggests that the mechanisms of coal adsorbing gas are different for the two pressure regions. The fractal dimension of the two regions is always calculated with the relative pressure of 0.5 as the dividing point (Yao et al. 2008). The results of the fractal dimension $D$ calculated by the FHH equation are illustrated in Table 5 . The calculation results obtained by the equation ' $A=D-3$ ' are between 2 and 3 , which is more reasonable than the calculation from the equation ' $A=(D-3) / 3$ '. It can be seen that $D_{1}$ is $2.296-2.534$ and $D_{2}$ is $2.651-2.912$.

Table 5 The fractal dimensions calculated by FHH model for low-temperature nitrogen desorption isotherms.

\begin{tabular}{cccccccccc}
\hline $\begin{array}{c}\text { Sample } \\
\text { no. }\end{array}$ & $\begin{array}{c}\text { Mean moisture } \\
\text { content } \%\end{array}$ & $A_{1}$ & $D_{1}=3+A_{1}$ & $D_{1}=3+3 A_{1}$ & $R^{2}$ & $A_{2}$ & $D_{2}=3+A_{2}$ & $D_{2}=3+3 A_{2}$ & $R^{2}$ \\
\hline YZG1 & 0 & -0.466 & 2.534 & 1.602 & 0.9533 & -0.088 & 2.912 & 2.737 & 0.9769 \\
YZG2 & 2.02 & -0.617 & 2.383 & 1.149 & 0.9594 & -0.123 & 2.877 & 2.632 & 0.9604 \\
YZG3 & 3.99 & -0.687 & 2.313 & 0.938 & 0.9543 & -0.134 & 2.866 & 2.599 & 0.9695 \\
YZG4 & 4.32 & -0.704 & 2.296 & 0.888 & 0.9649 & -0.127 & 2.873 & 2.619 & 0.9737 \\
YZG5 & 4.74 & -0.667 & 2.333 & 0.998 & 0.9605 & -0.193 & 2.807 & 2.421 & 0.9586 \\
YZG6 & 5.46 & -0.666 & 2.335 & 1.004 & 0.9561 & -0.147 & 2.853 & 2.558 & 0.9575 \\
YZG7 & 6.25 & -0.677 & 2.323 & 0.970 & 0.9629 & -0.216 & 2.784 & 2.351 & 0.9638 \\
YZG8 & 7.14 & -0.694 & 2.306 & 0.919 & 0.9826 & -0.196 & 2.804 & 2.412 & 0.9471 \\
YZG9 & 10.88 & -0.666 & 2.334 & 1.003 & 0.9914 & -0.349 & 2.651 & 1.952 & 0.9360 \\
\hline
\end{tabular}

The relationships between the fractal dimensions $D_{1}, D_{2}$ and moisture content are shown in Figure

8. When the moisture content is less than $4.74 \%$ (corresponding to $R H$ of $43 \%$ ), $D_{1}$ decreases rapidly, whereas $D_{2}$ reduces from 2.91 to 2.87 , showing a slight change. When the moisture content increases from $4.74 \%$ to $10.88 \%$ (corresponding to $R H$ of $98 \%$ ), $D_{2}$ decreases significantly, while $D_{1}$ remains at 


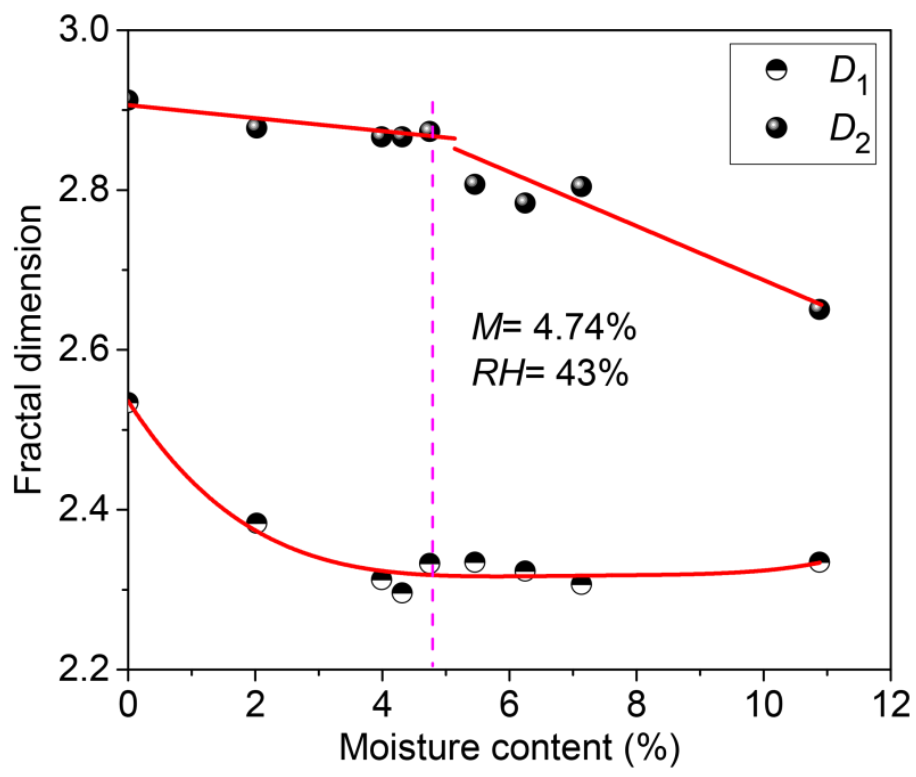

Water sorption on coal is gradually divided into the following stages (Liu et al. 2020): primary adsorption, secondary and even multilayer adsorption, the formation of water clusters, and capillary condensation of water. As illustrated in the section 4.1, when the $R H$ is lower than $43 \%$ (corresponding of equilibrium moisture content of $4.74 \%$ ), the adsorbed water content shows a Langmuir-type trend with an increase in $R H$, indicating that the water adsorption on coal mainly occurs on the primary sites, i.e., oxygen-containing functional groups (Charrière and Behra 2010; Švábová et al. 2011). In this process, water molecules are preferentially adsorbed on the surface of micropores, which can result in that the homogeneity of surface of micropores is enhanced for the water-equilibrated coal. This should be responsible for the significant reduction of fractal dimension $D_{1}$. As the relative humidity increases $(R H>43 \%)$, the secondary sites adsorption gradually turns into the main behavior. In this process, the formed water clusters grow continuously and capillary condensation will occurs. As shown in Figures 6 and 7, the PSDs curves of micropores shrinks close to the X-axis, while these of larger scale pores (pore diameter $>10 \mathrm{~nm}$ ) is basically unchanged. This shows that the water molecules adsorbing on the 

scale pores. However, the formed water clusters and capillary water will occupy the pore space and even fill some small pores and throat, thereby improving the homogeneity of pores structure. These should be responsible for the reduction in fractal dimension $D_{2}$ at high equilibrium moisture content be related to (i) the completion of saturated monolayer adsorption of water molecules on micropores; and (ii) the inability of gas molecules to pass through the pores and throat blocked by the adsorbed water.

\subsection{Impact of moisture on methane desorption performances}

\subsubsection{Methane desorption characteristics of moist coals}

The parameters $K_{1}, \Delta h_{2}$ are always selected as the methane desorption indices to predict the outburst risk of mining coal seams (Cheng et al. 2010). The two indices reflect the methane desorption performances of coal samples in the first minute $\left(Q_{1}\right)$ and the third to fifth minutes $\left(Q_{3-5}\right)$ (Chen and Cheng 2015; Jiang et al. 2015). The relationships between the initial desorption amounts $Q_{1}$ and $Q_{3-5}$ and moisture content are shown in Figure 9. The two desorption parameters decrease with moisture content in negative exponential form. In the range of the studied moisture content, the parameters $Q_{1}$ and $Q_{3-5}$ are reduced by $77.39 \%$ and $58.35 \%$. Namely, each $1 \%$ increase in moisture content can leads to about $11 \%$ reduction in $Q_{1}$ and about $8 \%$ reduction in $Q_{3-5}$, respectively. Therefore, moisture has a

358 weakening effect on the initial methane desorption capacity of coal, and $Q_{1}$ (corresponding to $K_{1}$ index) 


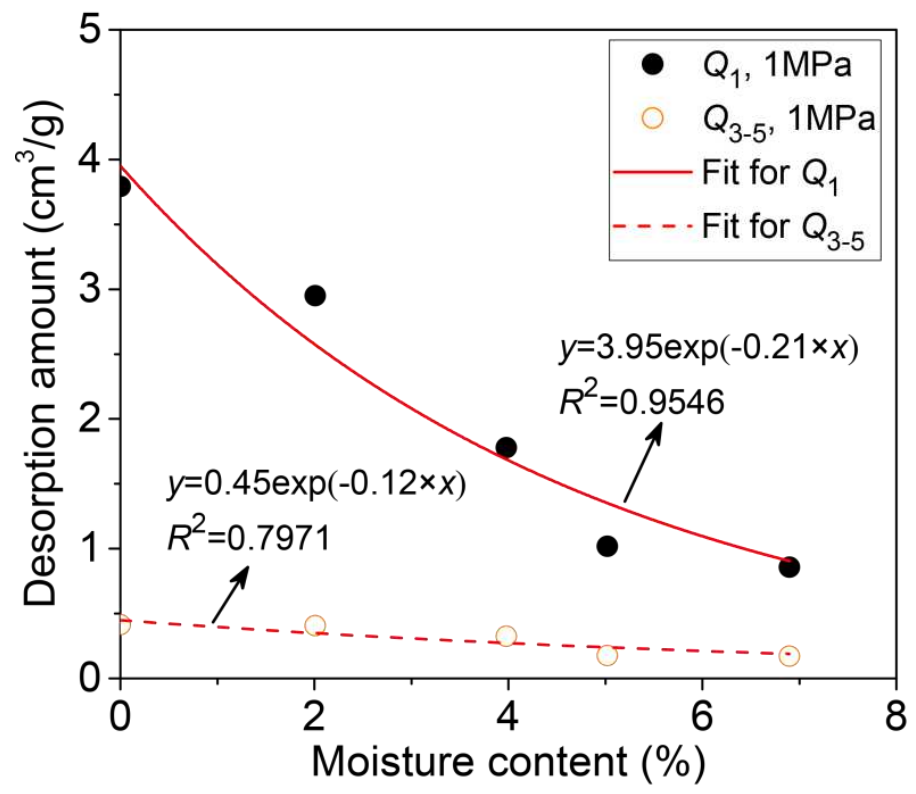

Figure 9 Relationships between $Q_{1}, Q_{3-5}$ and moisture content.

As shown in Figure 10, the relationships between methane desorption parameters $\left(V_{1}, A, K_{\mathrm{t}}\right)$ and moisture content at methane pressure of $1 \mathrm{MPa}$ are further studied. Below the studied moisture content, the ultimate desorption amount $(A)$ is decreased by about $0.66 \mathrm{~cm}^{3} / \mathrm{g}$ for each $1 \%$ increase in moisture content. For the initial desorption rate $\left(V_{1}\right)$, each $1 \%$ increase in moisture content can leads to a reduction of about $0.04 \mathrm{~cm}^{3} /(\mathrm{g} \cdot \mathrm{min})$. Water molecules have more adsorption advantages than methane molecules and can seize some adsorption spaces of gas molecules (Gensterblum et al. 2013; Gensterblum et al. 2014), thereby reducing the saturated adsorption capacity of moist coal. Furthermore, the reduction in gas adsorption capacity can decreases the concentration gradient of the desorbed gas and gas desorption amount (Liu et al. 2015; Xu et al. 2015), which should be responsible for that the initial desorption rate of low moisture content coal is higher than that of high moisture content coal. Besides, the desorption constant $K_{\mathrm{t}}$ shows a different change trend from the parameters $V_{1}$ and $A$. When the moisture content is less than $3.98 \%$, the parameter $K_{\mathrm{t}}$ decreases slightly, while it reduces significantly at the range of $3.98-6.9 \%$. As analyzed in the sections 4.3 .2 , this can be attributed to the fact that the constant $K_{\mathrm{t}}$ is mainly related to the fractal dimension $D_{2}$ representing the fractal 


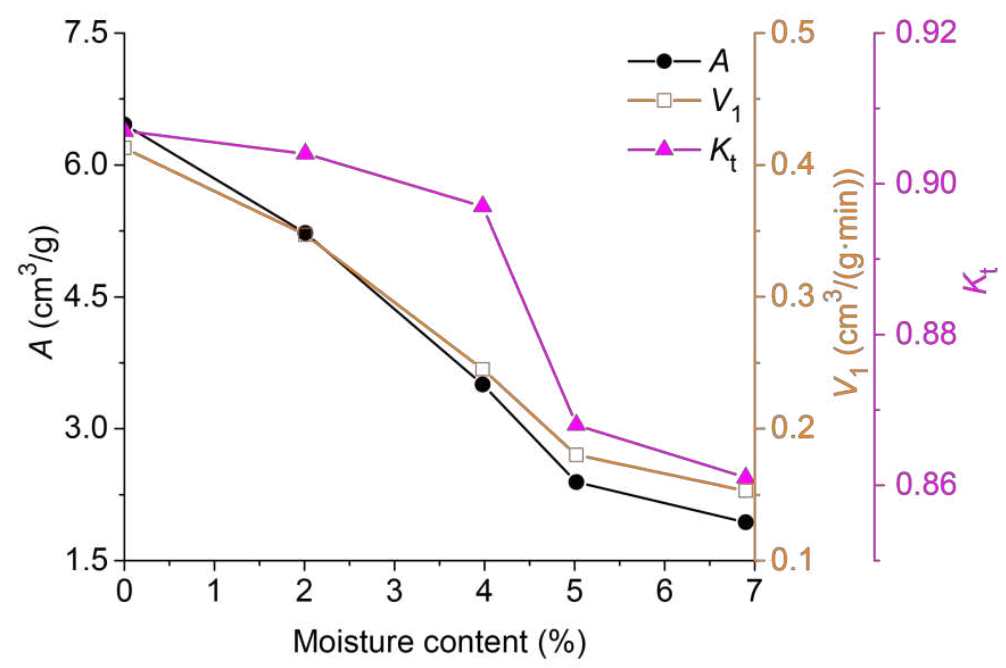

Figure 10 Changes in methane desorption parameters with moisture content.

\subsubsection{Relationship between fractal dimension and desorption parameters}

Many researchers have indicated that the methane desorption performances of coal is related to pore structure of coal under dry condition (Chen et al. 2017; Liu et al. 2022). In this paper, the Pearson product-moment correlation coefficient $(\gamma)$ is selected to further analyze the above relationship under moist condition. If the random variable $X=\left\{x_{1}, x_{2}, x_{3}, \ldots, x_{\mathrm{n}}\right\}, Y=\left\{y_{1}, y_{2}, y_{3}, \ldots, y_{\mathrm{n}}\right\}$, the Pearson correlation coefficient $(\gamma)$ for the two variables is defined as

$$
\gamma=\frac{n \sum x_{i} y_{i}-\sum x_{i} \sum y_{i}}{\sqrt{n \sum x_{i}^{2}-\left(\sum x_{i}\right)^{2}} \sqrt{n \sum y_{i}^{2}-\left(\sum y_{i}\right)^{2}}}
$$

where $n$ is the sequence length of the random variable, and $\gamma$ ranges from -1 to +1 . When $\gamma$ is 0 , the two variables are independent; when $\gamma$ is $[-1,0]$, the two variables are negatively correlated; and when $\gamma$ is $[0,+1]$, the two variables are positively correlated. The absolute value of $\gamma$ is close to 1 suggesting a higher correlation degree.

Combined with the interpolation method, the values of $\gamma$ between methane desorption parameters $\left(V_{1}, A, K_{\mathrm{t}}\right)$ and fractal dimensions $\left(D_{1}\right.$ and $\left.D_{2}\right)$ at gas pressure of $1 \mathrm{MPa}$ are calculated by SPSS software, as shown in Figure 9. The values of $\gamma$ for the correlations of $A$ and $D_{1}$ or $V_{1}$ and $D_{1}$ are larger 
393

394

395

than 0.8 , which are slightly higher than that for the correlations of $A$ and $D_{2}$ or $V_{1}$ and $D_{2}$. Conversely, the value of $\gamma$ for the correlation of $D_{2}$ and $K_{\mathrm{t}}$ is 0.780 , which is greater than that for the correlation of $D_{1}$ and $K_{\mathrm{t}}$. Therefore, the parameters $A$ and $V_{1}$ are more closely related to the fractal dimension $D_{1}$, whereas the desorption constant $K_{\mathrm{t}}$ is more dependent on the fractal dimension $D_{2}$. This is mainly due to that the fractal dimension $D_{1}$ and $D_{2}$ represents the surface fractal characteristic of micropores and the structural fractal characteristic of larger scale pores, respectively (Yao et al. 2008; Li et al. 2015).

The methane desorption parameters $A$ and $V_{1}$ reflect the ultimate and initial methane desorption capacities, which depend on the methane adsorption amount of coal (Liu et al. 2015). The micropores of coal plays a key role on methane adsorption capacity (An et al. 2013; Song et al. 2020), which provides an explanation for the close relationships between $D_{1}$ and $A, V_{1}$. Besides, the parameter $K_{\mathrm{t}}$ characterizes the ratio between the gas desorption volume in the macropores and micro-fractures in the first minute after methane gas is relieved (Guo et al. 2014). Chen et al. (2017) further suggested that the methane desorption constant $K_{\mathrm{t}}$ is associated with macropores volumes. Obviously, for both dry coal and water-equilibrated coal, the constant $K_{\mathrm{t}}$ is closely related to $D_{2}$ representing fractal dimension of larger scale pores.

Table 6 Correlation coefficients between fractal dimension and desorption parameters.

\begin{tabular}{cccc}
\hline Variables & $A$ & $V_{1}$ & $K_{\mathrm{t}}$ \\
\hline$D_{1}$ & $0.854^{* *}$ & $0.847^{* *}$ & $0.684^{* *}$ \\
$D_{2}$ & $0.727^{* *}$ & $0.729^{* *}$ & $0.780^{* *}$ \\
\hline
\end{tabular}
Note: $* *$ significance level $\alpha=0.01$.

Moreover, in the prevention and control of coal mine gas disasters, many desorption parameters are applied to assess the risk of coal and gas outburst. For example, for the desorption indices $\Delta h_{2}$ and $K_{1}$, the outburst critical values of moist coal $\left(\Delta h_{2}=160 \mathrm{~Pa}, K_{1}=0.4 \mathrm{~cm} /\left(\mathrm{g} \cdot \mathrm{min}^{0.5}\right)\right)$ are provided by some industrial standards (Cheng et al. 2010; Cheng et al. 2016). However, the loss and fluctuation of the adsorbed moisture in low-rank coal will affect the methane adsorption capacity of coal and 
sequentially lead to the variation in critical values of the desorption indices for outburst prediction. It's necessary to study the quantitative relationship between methane desorption indices and moisture content, and further put forward a reasonable method to determine the critical value of methane desorption indices of in-stiu coal seam. Another revelation is that developing new engineering technologies to reduce the water content of low-rank coal is also necessary to improve gas migration in the development of coalbed methane (CBM) (Guo et al. 2018).

\section{Conclusions}

(1) Both $\mathrm{N}_{2}-\mathrm{SSA}$ and $\mathrm{N}_{2}-\mathrm{PV}$ decrease significantly with equilibrium moisture content increases, and the adsorbed moisture has greater influence on coal's micropores with pore diameter less than 10 nm. In particular, when the adsorbed moisture content increases to $10.88 \%$ that is attained at $98 \%$ relatively humidity, the micropores less than $4 \mathrm{~nm}$ almost disappear in the DFT-PSDs probably due to the blocking effect of the formed water clusters and capillary water. However, the $\mathrm{N}_{2}$-SSA of micropores (pore diameter $<10 \mathrm{~nm}$ ) shows that it can still contributes most sites for gas adsorption on water-equilibrated coal at $98 \%$ relatively humidity.

(2) The fractal characteristics analyzed by the FHH model shows that, when the equilibrium moisture content is less than $4.74 \%$ (corresponding to a $R H$ of $43 \%$ ), $D_{1}$ decreases rapidly while $D_{2}$ shows a slight change, which is mainly due to the water adsorption on coal mainly occurs on the surface of micropores. Whereas, at high equilibrium moisture content $(M>4.74 \%)$, the $D_{2}$ decreases significantly and $D_{1}$ remains at about 2.32 with moisture content increases. The phenomenon can be attributed to the completion of monolayer adsorption of water molecules on micropores, and the pore-filling and pore-blocking effects of the adsorbed water in some pores and throat.

(3) The adsorbed moisture has significant negative impact on methane desorption capacity, and 
each $1 \%$ increase in moisture content can leads to about $11 \%$ reduction in $Q_{1}$ and about $8 \%$ reduction in $Q_{3-5}$. The analysis on the Pearson's correlation coefficient $(\gamma)$ shows that, below the studied equilibrium moisture content, the ultimate methane desorption capacity $(A)$ and initial desorption rate $\left(V_{1}\right)$ are closely related to $D_{1}$, while the desorption constant $K_{\mathrm{t}}$ mainly depends on $D_{2}$.

\section{Declarations}

Funding information: This work was supported by the National Natural Science Foundation of China (Grant No. 51804201, 52174230, 51904272), Natural Science Foundation of Hebei Province (Grant No. E2020210081; E2021210128), and the university-level Graduate innovation project (Grant No. YC2021029).

Author's contributions: Chen Ming-yi funding acquisition, Conceptualization, Methodology,

Writing-Reviewing and Editing; Yang Ya-pu Writing- Original Draft, Data Curation and analysis;

Chen Xiao-yun Data Curation and analysis; Tian Fu-chao Validation, supervision, Investigation; Sun

Wei-li experiment, Data Curation and analysis; Yang Yu-meng Validation, supervision, Investigation;

Zhang Tong-hao experiment.

Compliance with ethical standards:

Ethical approval Not applicable

Consent to participate Not applicable

Consent to publish Not applicable

Availability of data materials Not applicable

Competing interests The authors declare that they have no conflict of interest.

\section{Reference}

Airey E Gas emission from broken coal. An experimental and theoretical investigation. In: International Journal of Rock Mechanics and Mining Sciences \& Geomechanics Abstracts, 
1968. vol 6. Elsevier, pp 475-494

An FH, Cheng YP, Wu DM, Wang L (2013) The effect of small micropores on methane adsorption of coals from Northern China Adsorption 19:83-90

Andrade P RD, Lemus M R, PÉRez C CE (2011) MODELS OF SORPTION ISOTHERMS FOR FOOD: USES AND LIMITATIONS Vitae 18:325-334

Banerjee B (1988) Spacing of fissuring network and rate of desorption of methane from coals Fuel 67:1584-1586

Busch A, Gensterblum Y (2011) CBM and CO2-ECBM related sorption processes in coal: a review International Journal of Coal Geology 87:49-71

Charrière D, Behra P (2010) Water sorption on coals J Colloid Interface Sci 344:460-467

Chen MY, Cheng YP, Li HR, Wang L, Jin K, Dong J (2018) Impact of inherent moisture on the methane adsorption characteristics of coals with various degrees of metamorphism Journal of Natural Gas Science \& Engineering 55:312-320

Chen MY, Cheng YP, Zhou HX, Wang L, Tian FC, Jin K (2017) Effects of Igneous Intrusions on Coal Pore Structure, Methane Desorption and Diffusion within Coal, and Gas Occurrence Environmental \& Engineering Geoscience 23:191-207

Chen MY, Yang YP, Gao CH, Cheng YP, Wang JC, Wang N (2020) Investigation of the fractal characteristics of adsorption-pores and their impact on the methane adsorption capacity of various rank coals via $\mathrm{N}_{2}$ and $\mathrm{H}_{2} \mathrm{O}$ adsorption methods Energy Sci Eng doi:10.1002/ese3.727

Chen X, Cheng Y (2015) Influence of the injected water on gas outburst disasters in coal mine Nat Hazards 76:1093-1109

Chen Y, Tang DZ, Xu H, Tao S, Li S, Yang GH, Yu JJ (2015) Pore and fracture characteristics of different rank coals in the eastern margin of the Ordos Basin, China Journal of Natural Gas Science and Engineering 26:1264-1277 doi:10.1016/j.jngse.2015.08.041

Cheng LB, Wang L, Cheng YP, Jin K, Zhao W, Sun LS (2016) Gas desorption index of drill cuttings affected by magmatic sills for predicting outbursts in coal seams Arabian Journal of Geosciences 9 doi:10.1007/s12517-015-2133-8

Cheng YP, Pan ZJ (2020) Reservoir properties of Chinese tectonic coal: A review Fuel 260 doi:10.1016/j.fuel.2019.116350

Cheng YP, Wang HF, Wang L, Zhou HX, Liu HB, Wu DM, Li W (2010) Theories and Engineering Applications on Coal Mine Gas Control. China University of Mining and Technology Press, Xuzhou

Clarkson CR, Bustin RM (2000) Binary gas adsorption/desorption isotherms: effect of moisture and coal composition upon carbon dioxide selectivity over methane International Journal of Coal Geology 42:241-271 doi:https://doi.org/10.1016/S0166-5162(99)00032-4

Do DD, Do HD (2000) A model for water adsorption in activated carbon Carbon 38:767-773

Fu G, Xie XC, Jia QS, Tong WQ, Ge Y (2020) Accidents analysis and prevention of coal and gas outburst: Understanding human errors in accidents Process Saf Environ Protect 134:1-23 doi:10.1016/j.psep.2019.11.026

Gensterblum Y, Busch A, Krooss BM (2014) Molecular concept and experimental evidence of competitive adsorption of $\mathrm{H}_{2} \mathrm{O}, \mathrm{CO}_{2}$ and $\mathrm{CH}_{4}$ on organic material Fuel 115:581-588

Gensterblum Y, Merkel A, Busch A, Krooss BM (2013) High-pressure $\mathrm{CH}_{4}$ and $\mathrm{CO}_{2}$ sorption isotherms as a function of coal maturity and the influence of moisture International Journal of Coal Geology 118:45-57 
Guo H, Cheng Y, Wang L, Lu S, Jin K (2015) Experimental study on the effect of moisture on low-rank coal adsorption characteristics Journal of Natural Gas Science \& Engineering 24:245-251

Guo HJ et al. (2018) Effect of moisture on the desorption and unsteady-state diffusion properties of gas in low-rank coal Journal of Natural Gas Science and Engineering 57:45-51 doi:10.1016/j.jngse.2018.06.045

Guo J, Kang T, Kang J, Zhao G, Huang Z (2014) Effect of the lump size on methane desorption from anthracite Journal of Natural Gas Science and Engineering 20:337-346

Hong L, Gao DM, Wang JR, Zheng D (2019) The Power Source for Coal and Gas Outburst Journal of Mining Science 55:239-246 doi:10.1134/s1062739119025515

Huang CY, Zhang QY, Yan JM (1979) The study of pore structure analysis by water vapor adsorption-calculation of adsorption thickness and pore size distribution. J Chin Ceram Soc. 7:333-345

Jiang JY, Cheng YP, Mou JH, Jin K, Cui J, Rao ZH (2015) Effect of Water Invasion on Outburst Predictive Index of Low Rank Coals in Dalong Mine Plos One 10:e0132355

Jiang JY, Zhang Q, Cheng YP, Jin K, Zhao W, Guo HJ (2016) Influence of thermal metamorphism on CBM reservoir characteristics of low-rank bituminous coal Journal of Natural Gas Science and Engineering 36:916-930 doi:10.1016/j.jngse.2016.11.030

Kondo S, Ishikawa T, Abe I (2005) Adsorption science Chemical Industry Press, Beijing:84-85

Laxminarayana C, Crosdale PJ (2002) Controls on Methane Sorption Capacity of Indian Coals Aapg Bulletin 86:201-212

Li Y, Yang ZZ, Li XG (2019) Molecular Simulation Study on the Effect of Coal Rank and Moisture on $\mathrm{CO}_{2} / \mathrm{CH}_{4}$ Competitive Adsorption Energy \& Fuels 33:9087-9098

Li Z, Lin B, Gao Y, Cao Z, Cheng Y, Yu J (2015) Fractal analysis of pore characteristics and their impacts on methane adsorption of coals from Northern China International Journal of Oil, Gas and Coal Technology 10:306-324

Liu KQ, Zakharova N, Adeyilola A, Zeng LB (2021) Experimental Study on the Pore Shape Damage of Shale Samples during the Crushing Process Energy \& Fuels 35:2183-2191 doi:10.1021/acs.energyfuels.0c03297

Liu P, Liu A, Liu SM, Qi LL (2022) Experimental evaluation of ultrasound treatment induced pore structure and gas desorption behavior alterations of coal FUEL 307:121855 https://doi.org/10.1016/j.fuel.2021.121855

Liu SL, Zhang DF, Lun ZM, Zhao CP, Wang HT (2020) Occurrence of water within different rank coals: a review Energy Sources Part A-Recovery Util Environ Eff doi:10.1080/15567036.2020.1781979

Liu XF, Nie BS (2016) Fractal characteristics of coal samples utilizing image analysis and gas adsorption Fuel 182: 314-322

Liu YW, Feng GZ, Zuo WQ, Liu MJ, Mitri HS (2019) The law and mechanism of dynamic methane diffusion from coal particles under different moisture content Arabian Journal of Geosciences 12 doi:10.1007/s12517-019-4919-6

Liu YW, Zhang JQ, Liu MJ, Li YP (2015) Influence of moisture content on gas diffusion coefficient of coal particles with different metamorphic degree Journal of Safety Science and Technology 11: $12-17$

Lowell S, Shields JE, Thomas MA, Thommes M (2004) Characterization of porous solids and powders: surface area, pore size and density vol 16. Springer Science \& Business Media, Netherlands 
Lu S et al. (2021) Gas time-dependent diffusion in pores of deformed coal particles: Model development and analysis Fuel 295:120566 doi:https://doi.org/10.1016/j.fuel.2021.120566

Meng JQ, Li SC, Niu JX, Meng HX, Zhong RQ, Zhang LF, Nie BS (2020) Effects of moisture on methane desorption characteristics of the Zhaozhuang coal: experiment and molecular simulation Environ Earth Sci 79 doi:10.1007/s12665-019-8788-9

Ni GH, Li S, Rahman S, Xun M, Wang H, Xu YH, Xie HC (2020) Effect of nitric acid on the pore structure and fractal characteristics of coal based on the low-temperature nitrogen adsorption method Powder Technology 367:506-516 doi:10.1016/j.powtec.2020.04.011

Nie B, Liu X, Yuan S, Ge B, Jia W, Wang C, Chen X (2016) Sorption charateristics of methane among various rank coals: impact of moisture Adsorption 22:315-325

Pan Z, Connell LD, Camilleri M, Connelly L (2010) Effects of matrix moisture on gas diffusion and flow in coal Fuel 89:3207-3217

Qi LL, Tang X, Wang ZF, Peng XS (2017) Pore characterization of different types of coal from coal and gas outburst disaster sites using low temperature nitrogen adsorption approach International Journal of Mining Science and Technology 27:371-377 doi:10.1016/j.ijmst.2017.01.005

Si LL, Wei JP, Xi YJ, Wang HY, Wen ZH, Li B, Zhang HT (2021) The influence of long-time water intrusion on the mineral and pore structure of coal Fuel 290 doi:10.1016/j.fuel.2020.119848

Song DY, Ji XF, Li YB, Zhao HT, Song BY, He KK (2020) Heterogeneous development of micropores in medium-high rank coal and its relationship with adsorption capacity International Journal of Coal Geology 226 doi:10.1016/j.coal.2020.103497

Švábová M, Weishauptová Z, Přibyl O (2011) Water vapour adsorption on coal Fuel 90:1892-1899

Thommes M, Kaneko K, Neimark AV, Olivier JP, Rodriguez-Reinoso F, Rouquerol J, Sing KS (2015) Physisorption of gases, with special reference to the evaluation of surface area and pore size distribution (IUPAC Technical Report) Pure and Applied Chemistry 87:1051-1069

Wang BY, Qin Y, Shen J, Wang G (2017) Summarization of geological study on low rank coalbed methane in China Coal Science and Technology 45:170-179

Wang CY et al. (2021) Investigation of interactions between oxygen-containing groups and water molecules on coal surfaces using density functional theory Fuel 287 doi:10.1016/j.fuel.2020.119556

Wang F, Yao YB, Wen ZA, Sun QP, Yuan XH (2020a) Effect of water occurrences on methane adsorption capacity of coal: A comparison between bituminous coal and anthracite coal Fuel 266 doi:10.1016/j.fuel.2020.117102

Wang FK, Liang YP, Sun ZG, Li L, Li XL (2020b) Determination of the sensitivity index and its critical value for outburst risk prediction: A case study in Fuxiang mine, China Adsorpt Sci Technol 38:502-527 doi:10.1177/0263617420963735

Wang K, Zang J, Feng Y, Wu Y (2014a) Effects of moisture on diffusion kinetics in Chinese coals during methane desorption Journal of Natural Gas Science \& Engineering 21:1005-1014

Wang L, Chen ET, Liu S, Cheng YP, Cheng LB, Chen MY, Guo HJ (2017) Experimental study on the effect of inherent moisture on hard coal adsorption-desorption characteristics Adsorpt-J Int Adsorpt Soc 23:723-742 doi:10.1007/s10450-017-9889-y

Wang L, Cheng YP, Liu HY (2014b) An analysis of fatal gas accidents in Chinese coal mines Safety Science 62:107-113 doi:10.1016/j.ssci.2013.08.010

Winter K, Janas H (1975) Gas emission characteristics of coal and methods of determining the 
desorbable gas content by means of desorbometers. In: XIV International Conference of Coal Mine Safety Research, Sept. 22-26: Washington, D.C

Xiang JH, Zeng FG, Liang HZ, Li B, Song XX (2014) Molecular simulation of the CH4/CO2/H2O adsorption onto the molecular structure of coal Sci China-Earth Sci 57:1749-1759 doi:10.1007/s11430-014-4849-9

Xu H, Tang DZ, Zhao JL, Li S, Tao S (2015) A new laboratory method for accurate measurement of the methane diffusion coefficient and its influencing factors in the coal matrix Fuel 158:239-247 doi:10.1016/j.fuel.2015.05.046

Xue S, Zheng CS, Zheng XL, Jiang BY, Li YB, Wang ZG (2020) Experimental determination of the outburst threshold value of energy strength in coal mines for mining safety Process Saf Environ Protect 138:263-268 doi:10.1016/j.psep.2020.03.034

Yao Y, Liu D, Tang D, Tang S, Huang W (2008) Fractal characterization of adsorption-pores of coals from North China: an investigation on $\mathrm{CH} 4$ adsorption capacity of coals International Journal of Coal Geology 73:27-42

Yu JL, Tahmasebi A, Han YN, Yin FK, Li XC (2013) A review on water in low rank coals: The existence, interaction with coal structure and effects on coal utilization Fuel Processing Technology 106:9-20 doi:10.1016/j.fuproc.2012.09.051

Zhai C, Xiang XW, Xu JZ, Wu SL (2016) The characteristics and main influencing factors affecting coal and gas outbursts in Chinese Pingdingshan mining region Nat Hazards 82:507-530 doi:10.1007/s11069-016-2195-2

Zhang Y (2008) Geochemical kinetics. Princeton University Press, PRINCETON AND OXFORD

Zhang ZG, Cao SG, Li Y, Guo P, Yang HY, Yang T (2018) Effect of moisture content on methane adsorption- and desorption-induced deformation of tectonically deformed coal Adsorpt Sci Technol 36:1648-1668 doi:10.1177/0263617418800905

Zou LH, Gong LH, Xu P, Feng GC, Liu HM (2016) Modified GAB model for correlating multilayer adsorption equilibrium data Separation and Purification Technology 161:38-43 